\title{
Detection of Rabies Antigen in the Saliva and Brains of Apparently Healthy Dogs Slaughtered for Human Consumption and Its Public Health Implications in Abia State, Nigeria
}

\author{
P. P. Mshelbwala, ${ }^{1}$ A. B. Ogunkoya, ${ }^{1}$ and B. V. Maikai ${ }^{2}$ \\ ${ }^{1}$ Department of Veterinary Medicine, Ahmadu Bello University, Zaria, Nigeria \\ ${ }^{2}$ Department of Veterinary Public Health and Preventive Medicine, Ahmadu Bello University, Zaria, Nigeria
}

Correspondence should be addressed to P. P. Mshelbwala; philbwala@yahoo.com

Received 26 September 2013; Accepted 24 October 2013

Academic Editors: S. Chinikar, R. Klopfleisch, and S. Whisnant

Copyright (C) 2013 P. P. Mshelbwala et al. This is an open access article distributed under the Creative Commons Attribution License, which permits unrestricted use, distribution, and reproduction in any medium, provided the original work is properly cited.

\begin{abstract}
The study was carried out in eight dogs slaughtering outlets within four Local Government Areas of the State for the determination of rabies antigen in the saliva and brain of apparently healthy dogs slaughtered for human consumption. A total of one hundred (100) samples each of saliva and brain were collected before and after slaughter, respectively, between April to June, 2013, in the selected areas. The saliva was subjected to rapid immune-chromatographic test (RICT) while direct fluorescent antibody test (DFAT) was carried out on the brain samples. Structured questionnaire was administered to nineteen (19) dog meat processors comprising 18 males and 1 female in the selected areas. Sixty four percent of the samples tested were from female dogs while $36 \%$ were from males, $5 \%$ tested positive for rabies antigen with the use of both tests; there was no statistical association between sex and rabies status of the dogs sampled $(P>0.05)$. Butchers bitten during the course of slaughtering were $94.7 \%$ out of which $72.8 \%$ utilized traditional method of treatment and only $27.8 \%$ reported to the hospital for proper medical attention. This study has established the presence of rabies antigen in apparently healthy dogs in the study area.
\end{abstract}

\section{Introduction}

Rabies, though a vaccine preventable disease, still accounts for the death of over 50,000 people worldwide; $95 \%$ of these fatalities were apportioned to Africa and Asia [1] while 98\% of the cases were caused by rabies infected dog bite [2]. Worldwide, lines of evidence abound supporting the fact that dogs shed rabies virus in their saliva (Nottidge, 1994) [3]. Fekadu et al. [4] have established that rabies infected dogs that recovered shed rabies virus in their saliva intermittently, and this shedding continued for about 7 months while the dog remained apparently healthy; this represents a carrier status which was previously described in Nigeria [5]. Inapparent infection and recovery from clinical disease with resultant persistent or intermittent shedding of rabies virus have affected the overall effort in rabies eradication and control in most parts of the world [6-8]. The most dangerous aspect of carrier dogs is that bites from such dogs are usually not recognized as an exposure that will stimulate appropriate postexposure treatment. Consequently human deaths occur from exposure buried in an erratic incubation period where dogs show no sign suggestive of rabies [9].

Abia State shares border with Cross River State. Recently, 8 people died and the cause was traced to dog bite [10]. Those dogs were disposed off before reports got to Veterinary authorities, and it has been suggested that those suspected dogs must have been consumed before the onset of clinical signs thereby precluding confirmatory diagnosis [10].

Work on rabies in apparently healthy dogs has been carried out in different parts of the country [7, 11-13]. However, information on rabies in Abia State is wanting despite rabies outbreak in neighbouring states. There still exists an eclipse of information on rabies epidemiology in Abia state; there is therefore a need to find out the status of 
rabies in the state, especially carrier status. The study was undertaken to find out the presence of rabies antigen in the saliva and brain of apparently healthy dogs slaughtered for human consumption in Abia State and to find out the practices of dog meat slaughtering by butchers who fall within the high risk group.

\section{Materials and Methods}

2.1. Study Area. Located in the south-eastern part of Nigeria, Abia State lies within approximately latitudes $4^{\circ} 40^{\prime}$ and $6^{\circ} 14^{\prime}$ north of the equator and longitudes $7^{\circ} 10^{\prime}$ and $8^{\circ}$ east of the Greenwich meridian. The state shares common boundaries to the north with Ebonyi State; to the south and southwest with Rivers State; and to the east and southeast with Cross River and Akwa lbom States, respectively. To the west is Imo State and to the northwest is Anambra State. The state covers an area of about $5,243.7 \mathrm{sq} \cdot \mathrm{km}$ which is approximately 5.8 percent of the total land area of Nigeria. The study was carried out in Umuahia north, Ekwuano, Osisioma, and Isianlangwa north Local Government Areas of the State.

2.2. Sampling Method. Convenient random sampling as described by Mike [14] was employed. The most accessible units of the population were used. Live dogs bought or brought for slaughter were sampled in this designated Local Government Areas.

2.3. Use of Questionnaire. Structured questionnaire was administered to dog meat processors in the selected areas to obtain information on frequency of bite and method of treatment following bite.

\subsection{Processing of Samples}

2.4.1. Saliva. Saliva of dogs presented for slaughter was sampled using the sterile swab stick which was inserted into the mouth of the dog before slaughter. The swab was then inserted into an assay buffer tube and stirred to ensure a good sample extraction. The immune chromatographic test cassette was removed and placed horizontally. Using a sterile dropper, three drops of the extracted sample were dipped into the sample hole in the cassette, and the result was interpreted within 5-10 minutes according to manufacturer's instruction (BioNote). One hundred saliva samples were swabbed.

2.4.2. Brain. Brains of dogs, whose saliva was previously tested, were extracted using the method described by Kaplan and Koprowski [15]. It was then placed in polythene bag and transported to National Veterinary Research Laboratory, Vom Plateau State, and stored in a deep freezer for fluorescent antibody test. All stored samples were removed from the deep freezer and were allowed to thaw and smears were made on slides immediately after opening the brain and then subjected to fluorescent antibody test (FAT) as described by Dean et al. [16].
TABLE 1: Distribution of dogs samples according to sex and positivity in Abia state, Nigeria.

\begin{tabular}{lccc}
\hline Sex & Number tested & \multicolumn{3}{c}{ Number positive (\%) } \\
\hline Male & 36 & 0 & 0 \\
Female & 64 & 5 & 7.8 \\
\hline Total & 100 & 5 & 5 \\
\hline
\end{tabular}

TABLE 2: Breed and positivity distribution.

\begin{tabular}{lccc}
\hline Breed & Number tested & \multicolumn{2}{c}{ Number positive (\%) } \\
\hline Endogenous & 96 & 5 & 5.2 \\
Mixed & 3 & 0 & 0 \\
Exotic & 1 & 0 & 0 \\
\hline Total & 100 & 5 & $5 \%$ \\
\hline
\end{tabular}

TABLE 3: Dog meat processors previously bitten during slaughtering processes.

\begin{tabular}{lcc}
\hline & Number of butchers & Percentage (\%) \\
\hline Once bitten & 18 & 94.7 \\
Never Bitten & 1 & 5.3 \\
\hline Total & 19 & 100 \\
\hline
\end{tabular}

TABLE 4: Method of treatment for victims of dog bite.

\begin{tabular}{lcc}
\hline Method of treatment & Number of processors & Percentage \\
\hline Hospital & 5 & 27.8 \\
Traditional & 13 & 72.8 \\
\hline Total & 18 & 100 \\
\hline
\end{tabular}

2.5. Data Analysis. In this study, data generated were analyzed using the Statistical Package for Social science (SPSS) Version 17.0 to carryout descriptive analysis. Chi-square was used to test for association between categorical variables. Values of $P<0.05$ were considered significant.

\section{Result}

This study showed that out of the 100 dogs sampled more females (64\%) than males 36\% were slaughtered (Table 1). All the positive cases (5\%) were females and also were indigenous breeds (Table 2). There is a total agreement between the results obtained for DFAT and RICT for all the samples analysed in this study (Figure 1). None of the dogs meat processors were previously vaccinated against rabies; although the majority (94.7\%) were previously exposed to dog bite during the slaughtering process, only $5.3 \%$ were not exposed to dog bite (Table 3). On exposure to bite, $72.7 \%$ sought for traditional method of treatment while $27.8 \%$ reported to the hospital (Table 4); there was no significant association between sex of dogs slaughtered and positivity (0.08). Butchering was seen as occupation of male, although one of them happens to be a woman (Figure 2); there was no association between sex and butchering. The butcher's educational profile revealed the following: $68.4 \%$ had primary 


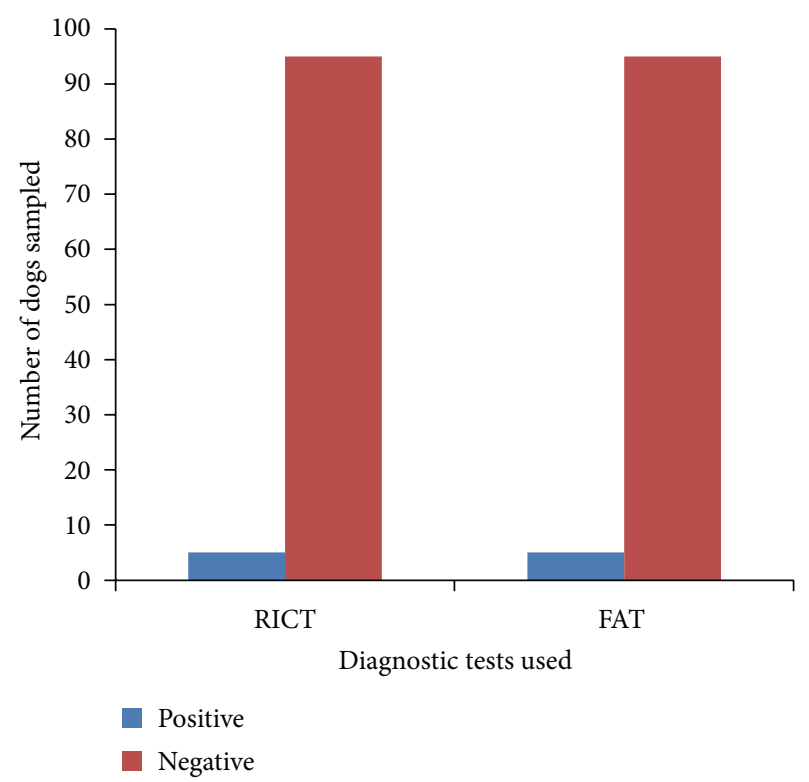

Figure 1: The results of the tests used for saliva and brain samples.

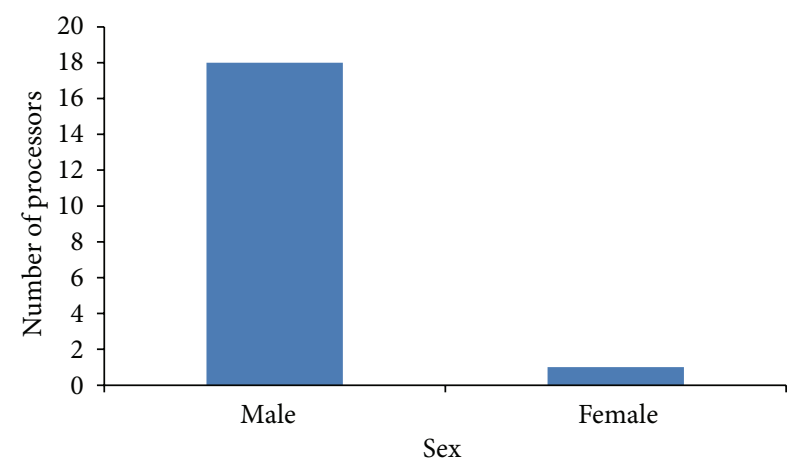

FIGURE 2: Sex distribution of processors of dog meat in Abia state.

education, $26.6 \%$ did not have any formal education, and $5.3 \%$ had tertiary education. Butchers handle dogs in a manner that exposed them to dog bite (Figure 3); on exposure to dog bite, butchers utilized traditional method of treatment, using traditional leaves and teethes of the offending dog, which is burnt to aches, mixed with native gin; part is given to the victim to drink and vomit while the rest is applied at the site of bite (Figure 4).

\section{Discussion}

The $5 \%$ prevalence of rabies antigen in the saliva and brains of apparently healthy dogs sold for human consumption in Abia State as demonstrated in this study is also in agreement with that of earlier work. [12] which established that apparently healthy dogs excrete rabies virus in their saliva for long period of time without showing clinical signs. Aghomo and Rupprecht [17] also reported lower prevalence in South Western Nigeria. In the study carried out in Ethiopia (Fekadu, 1975) dog inoculated with rabies virus recovered from clinical

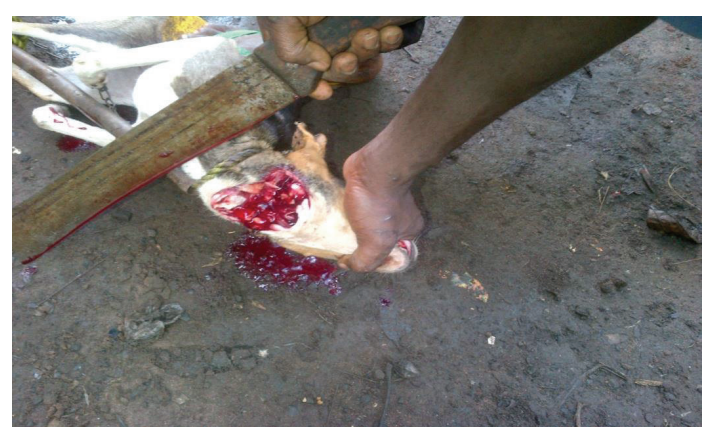

FIGURE 3: Butcher slaughtering dog for meat, using his bare hands to muzzle the mouth.

signs and continued to excrete rabies virus in its saliva. The result of this finding further suggests possible existence of carrier state among apparently healthy dogs in Abia State, Nigeria.

None of the butchers in this study were previously vaccinated against rabies, although majority of them (94.7\%) were previously bitten during the course of slaughtering which is in agreement with the findings of Garba et al. [18] in Northern Nigeria. Following dog bite, majority of the butchers sought traditional method of treatment, as against proper medical care, a practice which will further complicate the problem as none of the methods used have been tested to be effective. This is in agreement with the report of Ogunkoya [19]. In his report, he opined that traditional methods of treatment could militate against the control and eradication of rabies. The low educational level of the butchers could be the reason why they engaged in such practices.

Butchers in the study area handled dogs without taking adequate precaution which is the main reason why most of them sustained dog bite in the course of slaughtering; some even muzzled the dogs mouth using their bare hands, a practice which is capable of exposing them to bite or salivary contamination. This finding is similar to that of Garba et al. [18], Northern Nigeria. Rabies infection through skinning and handling of animals has been reported [20]. In our study, it can be seen that the manner in which butchers handled dogs before slaughter calls for concern, as this may further increase the likelihood of exposure to rabies.

The age, sex, breed, and location of dogs slaughtered during the course of the study were also considered. In this study, more females were slaughtered than males; this finding differs from the findings of Aliyu et al [12] and Ajayi et al. [7] in Northern Nigeria. The reason for attributing more females may be due to the practice of using male dogs for burial ceremony in some parts of the state, which makes the prices of male dogs go higher than females and also scarce. There was no association between sex and rabies status of the dogs sampled $(P>0.05)$. All the dogs sampled were sourced from their neighbourhood; this finding is in agreement with that of Garba et al. [18]; this is an indication that these dogs actually lived a normal life and continued to excrete the virus in their saliva without showing clinical signs. This form of rabies is the dangerous type as people are only aware of the violent form 


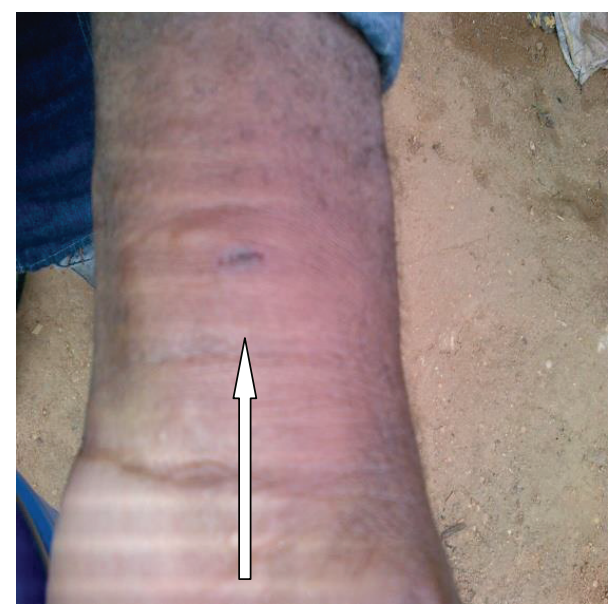

Site of dog bite

(a)

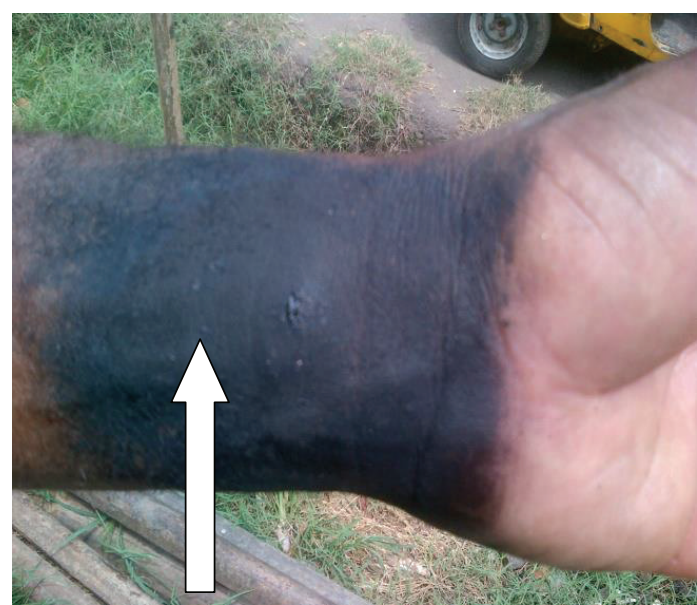

Traditional treatment

(b)

FIgURE 4: Site of dog bite sustained by dog meat processor in Abia state, Nigeria, and traditional treatment.

of rabies [19]. Human deaths from bites by owned dogs have been reported in Nigeria [21].

Dog butchering is seen as the business of male, but in this study, one of the butchers was a female and was pregnant at the time of sample collection. This finding differs from that of Garba et al. [18]; in their work males were seen as butchers. In northern Nigeria, females do not engage in some businesses based on religious restriction, especially Muslims; however in our studies in the eastern part of Nigeria, female movement is not restricted and there are no specifications of the type of business females are expected to engage in. Majority of the butchers had only primary education as only one had tertiary education; this could be the reason why they handled dogs without taking precaution. There is a total agreement between the results of all the tests used for rabies as all gave 5\% prevalence. In conclusion, this study has established the presence of rabies antigen in the saliva and brains of apparently healthy dogs slaughtered for human consumption in Abia State signifying its endemicity as it is in other states where studies have been conducted. This study also revealed the practices of dog slaughtering as a possible source of exposure to dog meat processors in Abia State. Hence mass enlightenment program for dog meat processors, consumers, and children in the state is highly recommended.

\section{Acknowledgments}

The authors are grateful to the staff of Animal World Veterinary Clinic, Abia State, for providing accommodation and facilities within the clinic to ensure that samples are kept in good condition before being transported to National Veterinary Research institute, for FAT. Special thanks are to Dr. Gurumyen Yilzem George, who was always there to receive the samples for onward delivery, and Mrs. Serah of the rabies laboratory who did the fluorescent antibody test.

\section{References}

[1] World Health Organisation, Rabies Fact Sheet 99, WHO, 2010, http://www.who.int/mediacentre/factsheets/en/.

[2] C. E. Rupprecht, "Current and future trends in the prevention, treatment and control of Rabies," in Book of Proceedings of National Conference and Workshop on Rabies, IDR-A.B.U, Zaria, Nigeria, 2008.

[3] M. Fekadu, "Pathogenesis of rabies virus infection in dogs," Reviews of Infectious Diseases, vol. 10, pp. S678-S683, 1988.

[4] M. Fekadu, J. H. Shaddock, F. W. Chandler, and G. M. Baer, "Rabies virus in the tonsils of a carrier dog," Archives of Virology, vol. 78, no. 1-2, pp. 37-47, 1983.

[5] Anon, "Rabies," Animal Report, Veterinary Department, Faculty of Veterinary Medicine Library, Colony and Protectorate of Nigeria, 1932.

[6] World Health Organisation, Expert Consultation on Rabies, WHO, 2005.

[7] B. B. Ajayi, J. S. Rabo, and S. S. Baba, "Rabies in apparently healthy dogs: histological and immunohistochemical studies," The Nigerian Postgraduate Medical Journal, vol. 13, no. 2, pp. 128-134, 2006.

[8] A. Nishizono, P. Khawplod, K. Ahmed et al., "A simple and rapid immunochromatographic test kit for rabies diagnosis," Microbiology and Immunology, vol. 52, no. 4, pp. 243-249, 2008.

[9] A. B. Ogunkoya, L. A. Will, and C. D. Ezeokoli, "Rabies in Oyo State, Nigeria; 1971-1982," International Journal of Zoonoses, vol. 11, no. 1, pp. 84-94, 1984.

[10] Office International des Epizooties, "Immediate notification report," REF OIE 12363, Nigeria, 2012.

[11] A. Garba, S. I. Oboegbulem, A. T. Elsa et al., "A comparative rabies laboratory diagnosis: peculiar features of samples from apparently healthy dogs in Nigeria," Sokoto Journal Veterinary of Sciences, vol. 7, no. 1, pp. 33-36, 2008.

[12] T. B. Aliyu, N. De, E. N. Yenda, and M. Lynn, Prevalence of Rabies Virus Antigens in Apparently Healthy Dogs in Yola, Nigeria, 2010, http://www.sciencepub.net/researcher.

[13] P. P. Mshelbwala, S. W. Audu, A. B. Ogunkoya et al., "A case study of rabies in a sixmonth old calf in Zaria, Nigeria," Journal 
of Experimental Biology and Agricultural Sciences, vol. 1, no. 4, pp. 218-222, 2013.

[14] B. Mike, Convininece Sampling: SAGE Research Method Online, 2011.

[15] M. M. Kaplan and H. Koprowski, "Rabies," Scientific American, vol. 2, pp. 103-114, 1980.

[16] D. J. Dean, M. K. Albelseth, and P. Atanasiu, “The Flourescent Antibody Test," in Laboratory Techniques in Rabies, F. X. Meslin, M. M. Kaplan, and H. Koprowski, Eds., pp. 88-89, Geneva World Health Organisation, 4th edition, 1996.

[17] H. O. Aghomo and C. E. Rupprecht, "Further studies on rabies virus isolated from healthy dogs in Nigeria," Veterinary Microbiology, vol. 22, no. 1, pp. 17-22, 1990.

[18] A. Garba, A. A. Dzikwi, P. A. Okewole et al., "Evaluation of dog slaughter and consumption practices related to the control of rabies in Nigeria," Journal of Experimental Biology and Agricultural Sciences, vol. 1, no. 2, pp. 125-130, 2013.

[19] A. B. Ogunkoya, "Rabies in Nigeria: problems and complications militating against its eradication and control," in Proceedings of the 1st National Conference of rabies in Nigeria, Faculty of Veterinary Medicine, Ahmadu Bello University, Zaria, Nigeria, September 2010.

[20] W. U. Z. Tariq, M. S. Shafi, S. Jamal, and M. Ahmad, "Rabies in man handling infected calf," The Lancet, vol. 337, no. 8751, p. 1224, 1991.

[21] A. B. Ogunkoya, S. W. Audu, M. O. V. Osinubi et al., "Two fatal cases of Rabies as a result of bites from apparently healthy dogs," in Proceedings of the World Rabies International, Global Alliance for Rabies Control WEBINAR, 2012. 

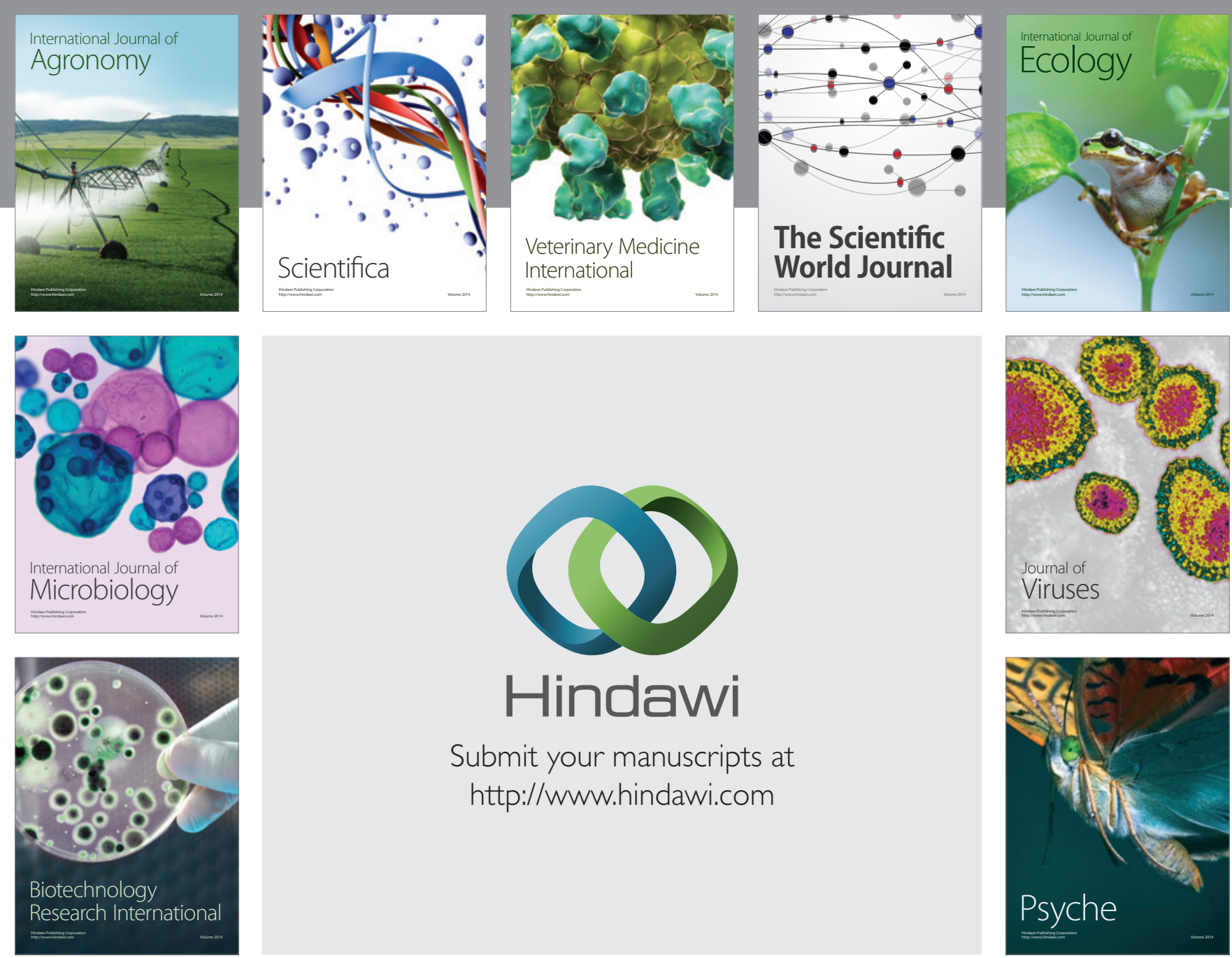

Submit your manuscripts at http://www.hindawi.com
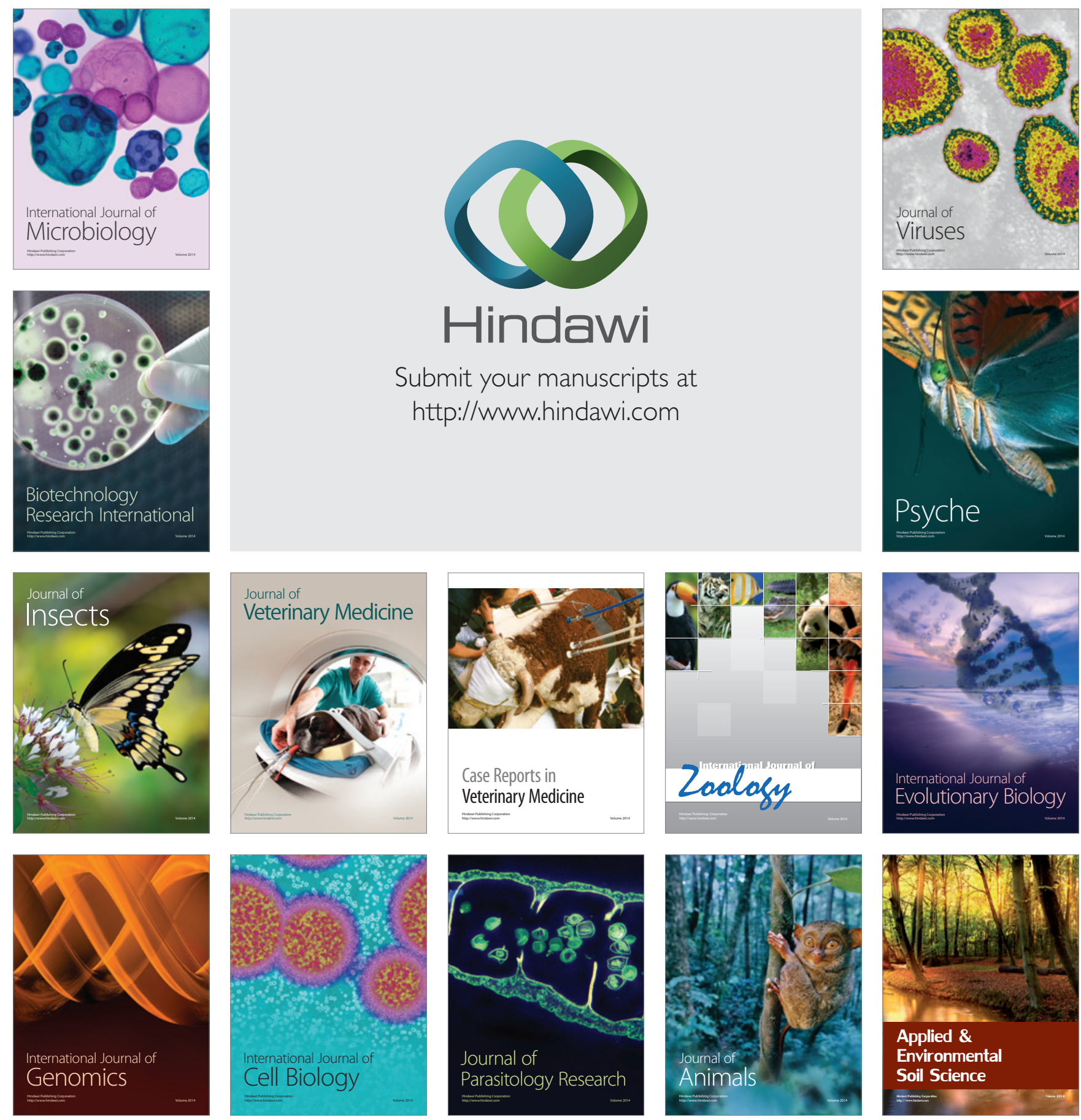